\title{
Effects of IL-10 on OX62, MHC-II and CD86 in bone marrow DCs in rats with organophosphate poisoning
}

\author{
NING WANG, JINFENG WANG and RONGGANG JIANG \\ Department of Electrophysiology, Cangzhou Central Hospital, Cangzhou, Hebei 061001, P.R. China
}

Received July 26, 2017; Accepted November 28, 2017

DOI: $10.3892 /$ etm.2017.5629

\begin{abstract}
This study investigated the effect of interleukin (IL)-10 on the expression of OX62, MHC-II and CD86 in bone marrow dendritic cells (DCs) in rats with organophosphorus poisoning. Sixty adult SD rats were randomly divided into normal control group (group A) (20 rats), 20 rats with organophosphorus pesticide poisoning (group B), 20 rats with organophosphorus poisoning, and IL-10 treated (group C). Group A was not treated with special treatment. Group B was treated with $4 \%$ omethoate by gavage to establish the model of organophosphate poisoning. Group $\mathrm{C}$ was treated with omethoate to establish the model of organophosphate poisoning, then the rats were given intraperitoneal injection of IL-10 for 3 continuous days. Rats were sacrificed after 3 days, bone marrow lymphocytes were extracted, DCs were collected and cultured for 7 days, the expression of DC surface antigen OX62, MHC-II, CD86 and related proteins was detected by flow cytometry and western blotting after cell maturation. The expression of DC surface antigen and corresponding protein increased in group B, and decreased in group C, the difference was statistically significant $(\mathrm{P}<0.05)$. The results showed that the expression of OX62, MHC-II and CD86 in bone marrow DCs is enhanced and the cellular immune function is enhanced after organophosphate poisoning. IL-10 can down-regulate the antigen presenting function of DCs, achieve anti-inflammatory effect and assist the treatment of organophosphorus pesticide poisoning.
\end{abstract}

\section{Introduction}

Organic phosphorus pesticide is a widely-used insecticide, it can enter the body through the respiratory tract, digestive tract, skin and mucous membranes, often leading to acute poisoning (1). According to statistics, organophosphate

Correspondence to: Dr Ning Wang, Department of Electrophysiology, Cangzhou Central Hospital, 16 Xinhua West Road, Cangzhou, Hebei 061001, P.R. China

E-mail:waz251@163.com

Key words: organophosphorus pesticide poisoning, interleukin 10, dendritic cells, OX62, MHC-II, CD86 poisoning patients globally are as high as 1-3 million each year, the mortality rate is $10 \%(2,3)$. Severe patients usually have poor prognosis, most of the deaths are closely related to the combination of multiple organ dysfunction syndrome (MODS) in its duration, proinflammatory and anti-inflammatory imbalance is one of the main causes of MODS (4).

Interleukin (IL)-10 is a multifunctional cytokine, it is an immunosuppressive factor that regulates the immune response of inflammatory responses (5). Studies have shown that, for patients with organophosphate poisoning, on the basis of detoxification drugs such as pralindoxime and atropine, the early use of IL-10 and other immunomodulators can effectively inhibit the body's excessive inflammatory response, reduce the immune system damage on their own tissue and organ, significantly improve patients' prognosis $(6,7)$. Dendritic cells (DCs) are the known most powerful antigen-presenting cells, mainly distributed in the myeloid tissue, and is closely related to the body's immune function (8). OX62, MHC-II, CD86 are closely related to DC antigen presentation function. In this study, we used recombinant rat IL-10 (rrIL-10) intervention organophosphate poisoning model to observe the effect on bone marrow DCs, providing theoretical basis for the clinical application and treatment of IL-10 in the treatment of organophosphorus poisoning.

\section{Materials and methods}

Experimental animals and groups. Sixty male adult CL Sprague-Dawley rats (Guangdong Provincial Medical Laboratory Animal Center) weighing 220-240 g were randomly divided into three groups by random number table method: 1) Normal control group (group $A, n=20$ ), and the weight of adult male Sprague-Dawley rats were randomly divided into: 2) organophosphate poisoning group (group B, $\mathrm{n}=20)$, 3) organophosphate poisoning IL-10 treatment group (group $\mathrm{C}, \mathrm{n}=20$ ). The breeding and final disposal of experimental animals conformed to the Ministry of Science and Technology's 'Guidance on Treat Experimental Animals'. The study was approved by the Ethics Committee of Cangzhou Central Hospital.

Main reagents and instruments. RPMI-1640 medium (Thermo Fisher Scientific, Waltham, MA, USA), fetal bovine serum (Thermo Fisher Scientific), rrIL-10 (Boehringer, Ingelheim, Germany), rrGM-CSF (Boehringer), mouse anti-rat Alexa 

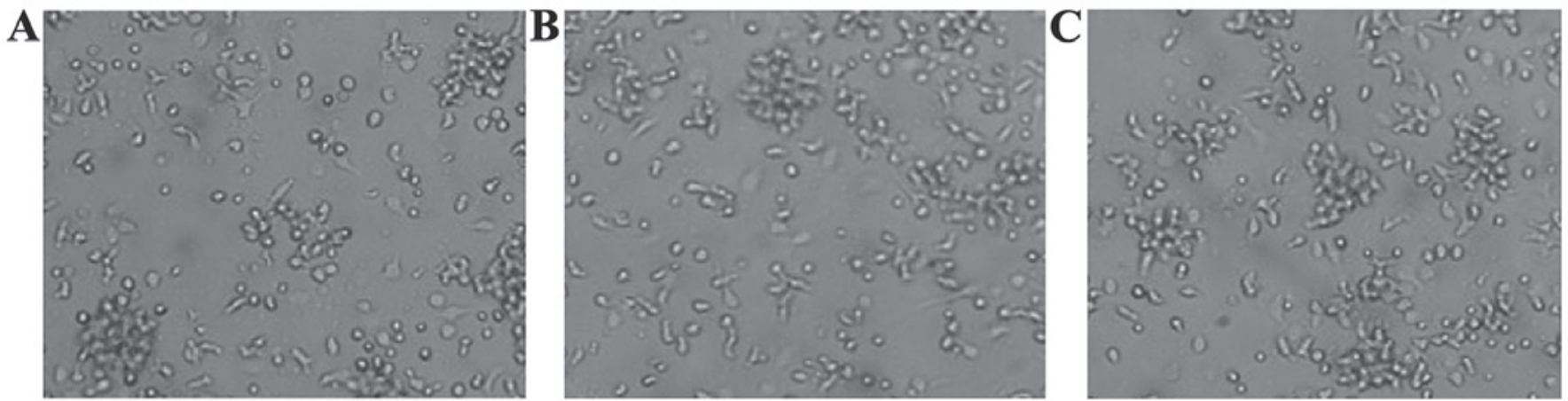

Figure 1. (A) Group A, (B) group B, (C) group C.

Fluor 647-labeled OX62 antibody, mouse anti-rat FITC-labeled MHC-II antibody (dilution, 1:100; cat. no. 205305), mouse anti-rat PE-labeled CD86 antibody (1:500; cat. no. 200308) all from (Biolegend, San Diego, CA, USA), mouse anti-rat OX62 (Sigma, St. Louis, MO, USA), mouse anti-rat MHC-II monoclonal antibody (dilution, 1:1,000; cat. no. SAB3500125), mouse anti-rat $\beta$-actin monoclonal antibody (dilution, 1:1,000; A5316) all from (Sigma, St. Louis, MO, USA), goat anti-mouse fluorescent secondary polyclonal antibody (dilution, 1:2,000; cat. no. 115-005-072; Jackson ImmunoResearch Inc., West Grove, PA, USA), 40\% omethoate EC (Chongqing Pesticide Chemical Co., Chongqing, China).

\section{Main method}

Animal model establishment. The omethoate EC was formulated into $0.4 \%$ gavage solution with $0.9 \%$ sodium chloride injection. Group B and group $\mathrm{C}$ were treated with gavage at median lethal dose $(45 \mathrm{mg} / \mathrm{kg})$, the occurrence of salivation, muscle fibrillation, dyspnea, standing instability and other neurological symptoms were the standards for the establishment of organic phosphorus poisoning model. Group A was given equal volume of saline gavage. After the establishment, group B was given intraperitoneal injection of rrIL-10 once a day at $2 \mu \mathrm{g} / \mathrm{kg}$ for 3 consecutive days. Group A and group C were given intraperitoneal injection of equal volume of saline.

DC collection and culture. Rats in each group were sacrificed after 3 days of establishment of the organophosphorus poisoning model. Animals were sacrificed by decapitation after anesthesia with intraperitoneal injection of $10 \%$ chloral hydrate. The bilateral lower limb femur and tibia were removed under strictly sterile conditions, the attached muscles were removed, the bones were soaked in $75 \%$ ethanol for two minutes. RPMI-1640 medium were used to rinse the bone marrow cavity until the liquid become colorless. The rinse solution was collected and centrifuged for $5 \mathrm{~min}$ at $1,200 \mathrm{x} \mathrm{g}$. The precipitated cells were collected and added with red cell lysate, stirred well, centrifuged for $5 \mathrm{~min}$ at 1,200 x g again. The supernatant was removed and RPMI-1640 whole medium was added for re-suspension, then added to the 6-well plate, cytokine $\mathrm{rrGM}-\mathrm{CSF}(40 \mathrm{ng} / \mathrm{ml}, 0.5 \mathrm{ml})$ and $\mathrm{rrIL}-4(50 \mathrm{ng} / \mathrm{ml}$, $0.2 \mathrm{~m}$ ) were added, incubated under $5 \% \mathrm{CO}_{2}$ volume fraction, $37^{\circ} \mathrm{C}$. The whole medium was replaced after $24 \mathrm{~h}$, after that, the solution was changed every half a day, supplemented with cytokines, cultured for 7 days.
Main observation indicators

Flow cytometry detection of DCs. The plate cells were digested by trypsin, washed twice with PBS and centrifuged for 5 min at $1,200 \mathrm{x}$. The supernatant was discarded and the cells were resuspended by PBS, added with fluorescently labeled MHC-II antibody, CD86 antibody and OX6 antibody, then incubated at $4^{\circ} \mathrm{C}$ in the dark for $30 \mathrm{~min}$, the excess antibody was washed away by PBS. The expression of OX62, MHC-II and CD86 in DCs was detected by flow cytometry.

Western blot detection of related protein expression. Cultured to the 7 th day, cells were scraped from the 6-well plate using a cell spatula. The protein lysate was added for collecting and extracting protein. BCA method was used to detect the concentration of each group. SDS polyacrylamide gel (12.5\%) was prepared, $40 \mu \mathrm{g}$ of total protein were taken as sample. $\beta$-actin was set as internal reference, after transferring, the membrane was closed for $2 \mathrm{~h}$ using $5 \%$ skim milk at room temperature, OX 62 (1:800), MHC-II (1:1,500), CD86 $(1: 1,200), \beta$-actin $(1: 100)$ antibodies were incubated at $4^{\circ} \mathrm{C}$ overnight, shaken and rinsed with TBST for 3 times, $2 \mathrm{~h}$ after incubation with se condary antibody, chemiluminescence reaction was performed, images were collected and analyzed after development.

Statistical analysis. Statistical analysis was performed using SPSS 17.0 software (IBM, Armonk, NY, USA). All data were expressed as mean \pm standard deviation. Comparison between multiple samples was analyzed by one-way ANOVA. LSD $\mathrm{t}$-test was used for multiple comparison. $\mathrm{P}<0.05$ was considered to indicate a statistically significant difference.

\section{Results}

The basic condition of rats after the establishment of the organophosphorus poisoning model. A total of 40 organophosphate poisoning models were established in group B and group $\mathrm{C}$, and the symptoms of organophosphorus poisoning such as salivation, muscle tremor, dyspnea and standing instability occurred at $10 \mathrm{~min}$ after omethoate gavage, peaked at $6 \mathrm{~h}$ and some rats died, then the symptoms are gradually reduced. Till drawing materials, 11 rats died in group B and 4 rats died in group C. The difference of mortality between the two groups was statistically significant $\left(\chi^{2}=5.23, \mathrm{P}=0.022<0.05\right)$. 
Table I. Flow cytometry detection of DC surface antigen $(n=8)$.

\begin{tabular}{llll}
\hline Group & OX62 $(\%)$ & MHC-II $(\%)$ & CD86 $(\%)$ \\
\hline A & $23.25 \pm 1.54$ & $31.24 \pm 2.31$ & $35.21 \pm 2.41$ \\
B & $45.31 \pm 2.17^{\mathrm{a}}$ & $44.69 \pm 1.94^{\mathrm{a}}$ & $41.31 \pm 2.12^{\mathrm{a}}$ \\
C & $36.12 \pm 1.96^{\mathrm{a}, \mathrm{b}}$ & $39.30 \pm 1.97^{\mathrm{a}, \mathrm{b}}$ & $39.53 \pm 1.94^{\mathrm{a}, \mathrm{b}}$
\end{tabular}

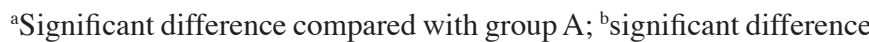
compared with group B.

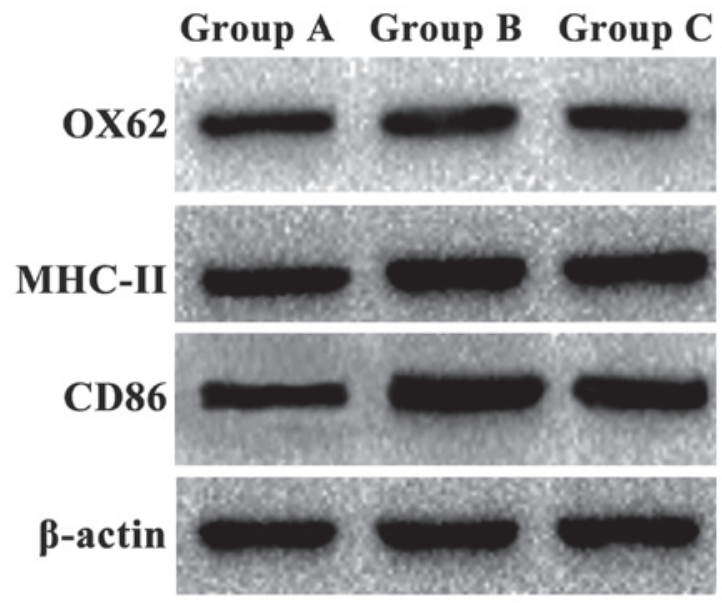

Figure 2. Western blot detection of protein expression results. The expression of OX62, MHC-II and CD86 protein in group B was significantly higher than that in group A, and the expression of OX62, MHC-II and CD86 in group C was lower than that in group B, but still higher than that in group A.

Morphological observation of DCs. Observed under inverted microscope, cells started adherent growth on the second day, clusters of cells gathered, arranged closely. On the 7th day, the cells showed typical DC morphological characteristics, suspension increased, a large number of irregular follicular protrusions appeared on the cell surface, some adherent cells could be gently blown off. Cell morphology and the number of cells in group A, B and C did not show significant difference (Fig. 1).

On the 7th day of DC culture, the suspension increased, showing clustered aggregation. There were no significant differences in the morphology and number of cells in each group.

Flow cytometry results. The surface antigen of OX62, MHC-II and CD86 in group B was significantly higher than that in group A by flow cytometry $(\mathrm{P}<0.05)$. The levels of OX62, MHC-II and CD86 in group C were lower than those in group $\mathrm{B}$, but still higher than that in group $\mathrm{A}(\mathrm{P}<0.05)$ (Table I).

Western blot results. The expression of OX62, MHC-II and CD86 protein in group B was significantly higher than that in group $\mathrm{A}(\mathrm{P}<0.05)$. The expression of OX62, MHC-II and CD86 in group $\mathrm{C}$ was lower than that in group $\mathrm{B}$, but still higher than that in group $\mathrm{A}(\mathrm{P}<0.05)$ (Fig. 2 and Table II).
Table II. Western blot detection of relative protein expression $(n=8)$.

\begin{tabular}{lccc}
\hline Group & OX62 (\%) & MHC-II (\%) & CD86 (\%) \\
\hline A & $27.34 \pm 1.63$ & $35.26 \pm 1.52$ & $33.31 \pm 2.01$ \\
B & $46.32 \pm 1.34^{\mathrm{a}}$ & $44.27 \pm 1.63^{\mathrm{a}}$ & $44.62 \pm 1.28^{\mathrm{a}}$ \\
C & $37.37 \pm 1.37^{\mathrm{a}, \mathrm{b}}$ & $38.25 \pm 1.46^{\mathrm{a}, \mathrm{b}}$ & $37.28 \pm 1.52^{\mathrm{a}, \mathrm{b}}$ \\
\hline
\end{tabular}

aSignificant difference compared with group A; ${ }^{\mathrm{b}}$ significant difference compared with group B.

\section{Discussion}

Organophosphorus poisoning is a common critical acute condition, the disease progresses quickly, without timely treatment it can deteriorate in a short time with high mortality (9). The poison combine with the cholinesterase after entering into the body, leading to cholinergic neurotransmitter mass accumulation at the neuromuscular junction, resulting in severe neurological disorders $(6,10)$. Most of these critical patients have combined MODS, and the prognosis is poor. The mechanism of secondary MODS after organophosphorus poisoning is usually considered to have cholinergic mechanism and non-cholinergic mechanism, some scholars have pointed out that non-cholinergic mechanism has a more obvious role in the process of causing damage to the body (11).

Dendritic cells (DCs) play a key role in cellular immunity as the only antigen-presenting cells that activate the 'initial' $\mathrm{T}$ lymphocytes in vivo $(12,13)$. DCs originate from lymphocytes and bone marrow cells, the former is related to B lymphocyte humoral immune function, the latter is associated with $\mathrm{T}$ lymphocyte immune function (14). In this study, we investigated the antigen-presenting function of DCs under the intervention of organic phosphorus and interleukin (IL)-10, so we selected myeloid DCs as the research object. OX62, MHC-II, CD86 and DCs are closely related to antigen presentation function. OX62 is a kind of adhesion molecules, which is essential for the determination of the subtype of DCs (15). MHC-II can effectively ingest and treat antigens to form peptide-MHC molecular complexes and then present antigen to helper $\mathrm{T}$ lymphocytes, so that $\mathrm{T}$ lymphocytes can obtain antigen stimulation signal to promote cell immunity, the level of MHC-II expression can reflect the antigen presenting function of DCs (16). CD86 can bind to CD28 on the surface of $\mathrm{T}$ cells, inducing $\mathrm{T}$ lymphocyte immune function activation, promoting immune response, its degree of expression can reflect the activation level of $\mathrm{T}$ lymphocyte immune function and can determine the ability of DCs to regulate the immune response $(12,17)$. Our experimental results showed that the expression of surface antigen and protein in bone marrow DCs of organophosphate poisoning rats was significantly increased, suggesting that in the pathophysiological process of organophosphate poisoning, the body may enhance the antigen presenting function of DCs through autoimmune regulation, thereby promoting $\mathrm{T}$ lymphocyte activation and differentiation, and enhance immune function. The imbalance of cellular immunomodulatory function 
after organophosphate poisoning is closely related to the occurrence and development of MODS. Due to imbalance in immune regulation function, abnormal amplification of inflammation occurs, a large number of inflammatory mediators are released, resulting in 'waterfall effect', the immune system attacks the body's own tissue, leading to organ dysfunction (18-20).

IL-10 is a kind of multi-functional negative immunoregulatory factor produced by the body. It is widely involved in the regulation of immune function in the body, can down regulating inflammatory response. It plays an important role in autoimmune diseases, severe infectious diseases, cancer and transplantation immune and other diseases by antagonizing the inflammatory mediators $(21,22)$. In the process of immune response, IL-10 can interfere with T lymphocyte activation by inhibiting the antigen presentation, reducing the body's inflammatory response $(23,24)$. For patients with severe organophosphate poisoning, early use of IL-10 and other immunomodulators can reduce the immune system damage to their own tissue $(12,25)$. We found that IL-10 intervention can reduce the expression of OX62, MHC-II and CD86 in bone marrow DCs of organophosphate poisoning rats. Therefore, we speculate that the use of IL-10 to reduce the immune system attack after organophosphate poisoning may be related to its ability to downregulate the immune response of DCs. We observed the effect of IL-10 on bone marrow DCs in organophosphate poisoning rats, but the molecular mechanism and signal pathway are not completely clear and needed further study.

\section{Acknowledgements}

This study was supported by Fund Project: Cangzhou Science and Technology Planning Project (162302030).

\section{References}

1. Srinivasan M, Amin R, Thunga G, Nagiri SK and Kudru CU: Pharmacokinetic potentiation of mixed organophosphate and pyrethroid poison leading to prolonged delayed neuropathy. J Clin Diagn Res 10: FD01-FD02, 2016.

2. Jaiprakash H, Sarala N, Venkatarathnamma PN and Kumar TN: Analysis of different types of poisoning in a tertiary care hospital in rural South India. Food Chem Toxicol 49: 248-250, 2011.

3. Lin CC, Hung DZ, Chen HY and Hsu KH: The effectiveness of patient-tailored treatment for acute organophosphate poisoning. Biomed J 39: 391-399, 2016.

4. Paraschos MD, Patrani M, Pistiki A, Katsenos C, Tsaganos T, Netea MG, Giamarellos-Bourboulis EJ and Mandragos K: Defective cytokine production early after multiple traumas: Modulation in severe sepsis. Cytokine 76: 222-226, 2015.

5. Iyer SS and Cheng G: Role of interleukin 10 transcriptional regulation in inflammation and autoimmune disease. Crit Rev Immunol 32: 23-63, 2012.

6. Yurumez Y, Ikizceli I, Sozuer EM, Soyuer I, Yavuz Y, Avsarogullari L and Durukan P: Effect of interleukin-10 on tissue damage caused by organophosphate poisoning. Basic Clin Pharmacol Toxicol 100: 323-327, 2007

7. Khajeh H, Bahari A, Lagzian M and Sabbagh SK: Functional and key gene expression analyses of chicken monocyte-derived dendritic cells with recombinant interleukin 4. Iran J Allergy Asthma Immunol 15: 508-514, 2016.
8. Hammer GE and Ma A: Molecular control of steady-state dendritic cell maturation and immune homeostasis. Annu Rev Immunol 31: 743-791, 2013.

9. Eddleston M, Buckley NA, Eyer P and Dawson AH: Management of acute organophosphorus pesticide poisoning. Lancet 371 : 597-607, 2008.

10. Hiremath P, Rangappa P, Jacob I and Rao K: Pseudocholinesterase as a predictor of mortality and morbidity in organophosphorus poisoning. Indian J Crit Care Med 20: 601-604, 2016.

11. Wang YT, Fu JJ, Li XL, Li YR, Li CF and Zhou CY: Effects of hemodialysis and hemoperfusion on inflammatory factors and nuclear transcription factors in peripheral blood cell of multiple organ dysfunction syndrome. Eur Rev Med Pharmacol Sci 20: 745-750, 2016.

12. Puhr S, Lee J, Zvezdova E, Zhou YJ and Liu K: Dendritic cell development - History, advances, and open questions. Semin Immunol 27: 388-396, 2015.

13. Xu X, Gao Y, Shan F and Feng J: A novel role for RGMa in modulation of bone marrow-derived dendritic cells maturation induced by lipopolysaccharide. Int Immunopharmacol 33: 99-107, 2016.

14. Gaignage M, Marillier RG, Uyttenhove C, Dauguet N, Saxena A, Ryffel B, Michiels T, Coutelier JP and Van Snick J: Mouse nidovirus LDV infection alleviates graft versus host disease and induces type I IFN-dependent inhibition of dendritic cells and allo-responsive T cells. Immun Inflamm Dis 5: 200-213, 2017.

15. Fazal $\mathrm{N}$ : $\mathrm{OX} 62^{+} \mathrm{OX} 6^{+} \mathrm{OX} 35^{+}$rat dendritic cells are unable to prime $\mathrm{CD}^{+} \mathrm{T}$ cells for an effective immune response following acute burn injury. Results Immunol 3: 64-72, 2013.

16. Clement CC, Becerra A, Yin L, Zolla V, Huang L, Merlin S, Follenzi A, Shaffer SA, Stern LJ and Santambrogio L: The dendritic cell major histocompatibility complex II (MHC II) peptidome derives from a variety of processing pathways and includes peptides with a broad spectrum of HLA-DM sensitivity. J Biol Chem 291: 5576-5595, 2016.

17. Silva AM, Almeida MI, Teixeira JH, Maia AF, Calin GA, Barbosa MA and Santos SG: Dendritic cell-derived extracellular vesicles mediate mesenchymal stem/stromal cell recruitment. Sci Rep 7: 1667, 2017.

18. Oliynyk OV, Pereviznyk BO, Yemiashev OV and Shlifirchyk A: The effectiveness of corticosteroid usage in complex therapy for severe sepsis and acute respiratory distress syndrome in cases of severe traumatic brain injury. Adv Clin Exp Med 25: 1223-1226, 2016.

19. Guzel M, Akar H, Erenler AK, Baydin A and Kayabas A: Acute ischemic stroke and severe multiorgan dysfunction due to multiple bee stings. Turk J Emerg Med 16: 126-128, 2016.

20. Rovasio L, Framarini S and Baccaro F: Multiple organ dysfunction in acute organophosphate poisoning. Med Intensiva 35: 450-452, 2011 (In Spanish).

21. Liu CH, Kuo SW, Ko WJ, Tsai PR, Wu SW, Lai CH, Wang CH, Chen YS, Chen PL, Liu TT, et al: Early measurement of IL-10 predicts the outcomes of patients with acute respiratory distress syndrome receiving extracorporeal membrane oxygenation. Sci Rep 7: 1021, 2017.

22. Neuper T, Ellwanger K, Schwarz H, Kufer TA, Duschl A and Horejs-Hoeck J: NOD1 modulates IL-10 signalling in human dendritic cells. Sci Rep 7: 1005, 2017.

23. Conaway EA, de Oliveira DC, McInnis CM, Snapper SB and Horwitz BH: Inhibition of inflammatory gene transcription by IL-10 is associated with rapid suppression of lipopolysaccharideinduced enhancer activation. J Immunol 198: 2906-2915, 2017.

24. Stanilov NS, Miteva L, Cirovski G and Stanilova SA: Increased transforming growth factor $\beta$ and interleukin 10 transcripts in peripheral blood mononuclear cells of colorectal cancer patients. Contemp Oncol (Pozn) 20: 458-462, 2016.

25. Kim MK, Yoon KA, Park EY, Joo J, Lee EY, Eom HS and Kong SY: Interleukin-10 polymorphisms in association with prognosis in patients with B-Cell lymphoma treated by R-CHOP. Genomics Inform 14: 205-210, 2016. 